\title{
Isolated Brain Trauma in Cats Triggers Rapid Onset of Hypovolemia
}

\author{
Peter Bentzer $^{1,2} \cdot$ Per-Olof Grände ${ }^{2}$
}

Published online: 7 November 2016

(c) The Author(s) 2016. This article is published with open access at Springerlink.com

\begin{abstract}
Background Hemodynamic instability responsive to fluid resuscitation is common after a traumatic brain injury (TBI), also in the absence of systemic hemorrhage. The present study tests if an isolated severe TBI induces a decrease in plasma volume (PV).

Methods The study was performed in three groups of anesthetized and tracheostomized male cats $(n=21)$. In one group $(n=8)$, the cats were prepared with a cranial borehole $(10 \mathrm{~mm}$ i.d) used to expose the brain to a fluid percussion brain injury (FPI) (1.90-2.20 bar), and two smaller cranial boreholes (4 $\mathrm{mm}$ i.d) for insertion of an intracranial pressure (ICP) and a microdialysis catheter. To differentiate the effect of FPI from that of the surgical preparation, a sham group was exposed to the same surgical preparation but no FPI trauma $(n=8)$. A control group had no brain trauma and no surgical preparation $(n=5)$. PV was determined by a ${ }^{125} \mathrm{I}$-albumin dilution technique. $\mathrm{PV}$, electrolytes, $\mathrm{pH}, \mathrm{BE}$ (base excess), hematocrit (Hct), $\mathrm{P}_{\mathrm{a}} \mathrm{O}_{2}$, and $\mathrm{P}_{\mathrm{a}} \mathrm{CO}_{2}$ were measured at baseline and after $3 \mathrm{~h}$. Mean arterial pressure (MAP) was measured continuously. ICP was measured in the FPI and the sham group.

Results In the FPI group, PV decreased by $11.2 \mathrm{~mL} / \mathrm{kg}$ from $31.7 \mathrm{~mL} / \mathrm{kg}(p<0.01)$ with a simultaneous increase
\end{abstract}

Per-Olof Grände

per-olof.grande@med.lu.se

1 Department of Clinical Sciences, Anesthesiology and Intensive Care, Helsingborg Hospital, Lund University, Lund, Sweden

2 Department of Clinical Sciences, Anesthesiology and Intensive Care, Lund University Hospital, Lund University, 22185 Lund, Sweden in Hct and decrease in $\mathrm{pH}$. In the sham group, PV decreased by $5.7 \mathrm{~mL} / \mathrm{kg}$ from $32.7 \mathrm{~mL} / \mathrm{kg}(p<0.01)$. The control group showed no PV reduction.

Conclusions The results support that an isolated severe head trauma triggers a significant and rapid reduction in $\mathrm{PV}$, most likely due to vascular leak.

Keywords Traumatic brain injury · Plasma volume . Fluid percussion trauma $\cdot$ Intracranial pressure . Blood pressure · Vascular leak

\section{Introduction}

Brain damage following a TBI is both an initial direct mechanical injury and a subsequent secondary brain injury $[1,2]$. The secondary injury includes an inflammatory response with release of a host of cytokines and a profound acute-phase response, which is thought to contribute to disruption of the blood-brain barrier and brain edema [2-7]. Release of inflammatory substances from the brain may also cause a systemic inflammatory response syndrome (SIRS) with a general increase in transcapillary leak of fluid and proteins and development of hypovolemia [8-10]. A low PV may lead to adverse effects due to reduced cardiac output and activation of the baroreceptor reflex with increased sympathetic discharge and release of catecholamines, resulting in general vasoconstriction also including the brain [11]. Especially, injured parts of the brain suffering compromised circulation may be uniquely sensitive to hypovolemia [11].

The hypothesis that an isolated TBI may induce systemic inflammation with systemic transcapillary leak of albumin is supported by the observation that albumin concentration in plasma is commonly decreased shortly 
after a TBI [12]. The clinical experience that fluid administration often restores hemodynamic stability in patients with TBI, also in the absence of major systemic hemorrhage, is compatible with hypovolemia [13, 14]. Plasma volume substitution is also an important component in modern head trauma guidelines $[15,16]$.

In spite of the fact that significant hypovolemia may develop in TBI and clinical signs are compatible with hypovolemia, there are no data available on the development and significance of hypovolemia in the setting of isolated TBI.

The present study on the anaesthetized cat tested the hypothesis that an isolated TBI in terms of a standardized fluid percussion brain injury (FPI) [17-19] without intracranial hemorrhage is associated with a reduction in PV. To separate effects of the brain trauma from those induced by the surgical preparation, three groups of animals were studied; one group subjected to the surgical preparation followed by a brain trauma, one group subjected only to the surgical preparation (no brain trauma), and one control group exposed only to tracheostomy and arterial and venous cannulation.

\section{Materials and Methods}

\section{Anesthesia and Experimental Procedure}

The study was approved by the Ethics Committee for Animal Research at Lund University, Sweden (application no M61-12). The animals were treated in accordance with the Guidelines for Care and Use of Laboratory Animals of the National Academy of Sciences. Twenty-one adult male cats weighing $3.7-5.0 \mathrm{~kg}(4.4 \pm 0.4 \mathrm{~kg})$ were included in the study. The cats were given food up to $12 \mathrm{~h}$ before and water up to $1 \mathrm{~h}$ before the start of the experiment. There was no significant difference in weight between the three groups. Anesthesia was induced with ketamine (4 mg/kg) given intramuscularly. A catheter was inserted into a subcutaneous vein of the left forelimb, and anesthesia was continued using alpha-chloralose $(50 \mathrm{mg} / \mathrm{kg}$ bolus followed by an infusion of $4 \mathrm{mg} / \mathrm{kg} / \mathrm{h}$ ) given intravenously. After tracheostomy, the animals were ventilated with air using a volume-controlled ventilator (Ugo Basile, Comerio-Varese, Italy), maintaining an approximately constant end-tidal $\mathrm{PCO}_{2}$ within the normal range of $36-40 \mathrm{mmHg}$ (4.8-5.3 kPa) $\left(\mathrm{CO}_{2}\right.$ Analyzer; MedAir, Delsbo, Sweden). The animals were placed on a heating pad, and body core temperature was kept constant at $37.3-37.6{ }^{\circ} \mathrm{C}$ through a feedback circuit controlled by continuous measurement via a temperature probe inserted in the esophagus. The animals were given $5 \mathrm{~mL} / \mathrm{kg} / \mathrm{h}$ of $0.9 \% \mathrm{NaCl}$ intravenously as fluid substitution starting after initiation of anesthesia and lasting up to the end of the experiment. Mean arterial blood pressure (MAP) was recorded continuously throughout the experiment via a catheter inserted into the left brachial artery and filled with heparinized fluid. Arterial blood samples were taken from this catheter.

\section{Fluid Percussion Brain Injury (FPI)}

A traumatic brain injury was induced using a FPI model as described previously [17-19]. Briefly, after a midline scalp incision over the parietal bone, the scalp and the temporal muscles were dissected free from the cranium in a circular area of about $2.5 \mathrm{~cm}$ in diameter. A borehole of $10 \mathrm{~mm}$ in diameter used for the FPI trauma was drilled in the skull just to the left of the midline down to the dura. The dura was intact in all the animals. One borehole with a diameter of $4 \mathrm{~mm}$ was drilled close to the $10-\mathrm{mm}$ hole down to the dura, and another 4-mm borehole was drilled to the right of the midline (Fig. 1). The scalp incision and drilling of the boreholes only resulted in minor bleeding. A 10-mm metal adapter with an external screw thread and an inner hole of $8 \mathrm{~mm}$ in diameter was screwed into the large hole and further attached to the skull bone with dental cement. The animals were now connected to the trauma device via the metal adaptor, after assuring that the whole fluid system from the piston to the dura was free from air (Fig. 1). The piston was hit by a 4.4-kg pendulum from a specific fall height, producing a brief pressure pulse $(25 \mathrm{~ms})$ via the fluid column onto the exposed dura and underlying brain. A pressure transducer connected to the fluid column measured the applied pressure (Fig. 1). Peak pressures were found to be in the range of 1.90-2.20 bars (2.05 \pm 0.13 bar).

After injury, the metal adaptor was removed from the scalp. A microdialysis catheter with an external diameter of $0.5 \mathrm{~mm}$ and length of $10 \mathrm{~mm}$ was placed via the small left borehole (CMA/20; CMA Microdialysis, Stockholm, Sweden) (Fig. 1) in the cortex. An ICP-measuring parenchymal transducer (Codman and Shurleff, Raynham, MA) was inserted in the brain 6-8 $\mathrm{mm}$ below the dura via the small right borehole (Fig. 1). All the boreholes were then sealed with histacryl to prevent leakage of cerebrospinal fluid and bleeding from the bone borders. Due to technical failure in the analysis of the microdialysis samples, no microdialysis data can be presented.

\section{Plasma Volume (PV)}

PV was determined with a well-established technique [20-23] by measuring the increase in radioactivity in $500 \mu \mathrm{L}$ of plasma taken 5 min after an intravenous injection of human ${ }^{125}$ I-albumin with a known amount of activity. The increase in radioactivity was calculated by 

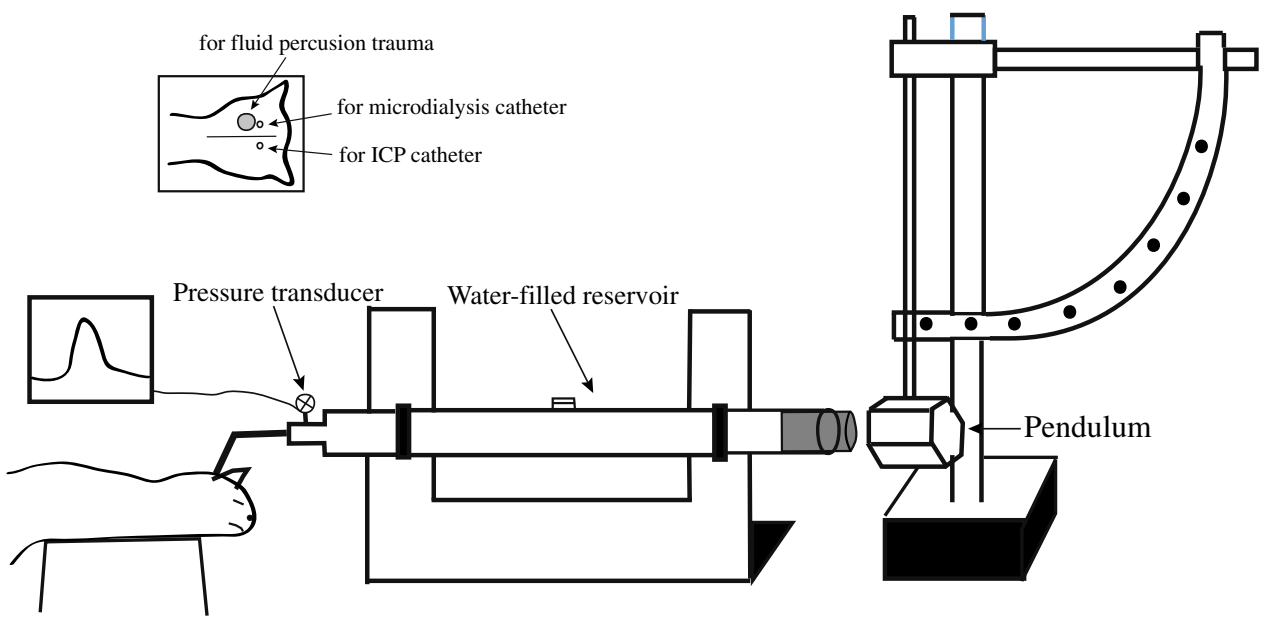

Fig. 1 Schematic illustration of the fluid percussion model of mechanical brain injury. A metal adaptor with a hole of $8 \mathrm{~mm}$ in diameter was fixed in the cranium and was in fluid connection via a metal tubing to a Plexiglass cylinder filled with physiological saline free from air bubbles. The other end of the cylinder is occluded by a

subtracting the activity in a blood sample taken just before the injection from that taken 5 min after the injection. Each PV measurement was thereby adjusted for remaining radioactivity from previous measurements. To calculate the amount of radioactivity given, the remaining radioactivity in the emptied vial, syringe, and needle used was measured and subtracted from the total radioactivity in the prepared dose. This is a reliable and established technique for PV measurement with small sources of error and reproducible results [20, 21, 23] (see "Discussion" section). Free iodine following precipitation with $10 \%$ trichloroacetic acid was measured regularly and was found to be less than $1.6 \%$ in all experiments. Radioactivity was measured with a gamma counter (Wizard 1480; LKB-Wallace, Turku, Finland). Plasma volume in blood samples taken to measure PV and electrolytes from the start to the end of the experiment was calculated to be about $0.6 \mathrm{~mL} / \mathrm{kg}$.

\section{Protocol}

The study was performed in three randomized groups of animals. One group called "the FBI group" was exposed to a FPI trauma as described above. Another group called "the sham group" was exposed to the same experimental procedures as in "the FBI group" (anesthesia, cranial boreholes, arterial and venous cannulations, and tracheostomy) but was not exposed to a brain trauma. A third group called "the control group" was anesthetized, cannulated, and tracheostomized as in the other groups; but there was no trauma in terms of scalp incision, cranial boreholes, and FPI.

PV was measured at baseline in the three groups. It was also measured $3 \mathrm{~h}$ after trauma in "the FBI group" and at corresponding time point for "the sham group" and "the
Plexiglass cork mounted on O-rings. Injury is produced by striking the cork with a 4.4-kg pendulum dropped from a known fall height. The pressure in the cylinder is recorded via an extracranial pressure transducer on a screen

control group." Sodium/s, potassium/s, $\mathrm{P}_{\mathrm{a}} \mathrm{O}_{2}, \mathrm{P}_{\mathrm{a}} \mathrm{CO}_{2}, \mathrm{pH}$, base excess (BE), and hematocrit (Hct) were measured from arterial blood samples taken at baseline and at the end of the experiment $3 \mathrm{~h}$ later. MAP was measured continuously from the start to the end of the experiment in all groups. ICP was measured in "the FBI group" and "the sham group" from the start to the end of the experiment. MAP and ICP were recorded on a Grass polygraph. After finishing the experiment, the cats were euthenized with an intravenous bolus infusion of $3 \mathrm{M} \mathrm{KCl}$.

\section{Statistical Analysis}

Data are presented as mean \pm SD. Student's $t$ test for paired observations was used for comparison of PV, Hct, $\mathrm{pH}, \mathrm{P}_{\mathrm{a}} \mathrm{O}_{2}, \mathrm{P}_{\mathrm{a}} \mathrm{CO}_{2}, \mathrm{BE}$, and electrolytes at baseline and at the end of the experiments for all three groups. Student's $t$ test for unpaired observations was used for comparing PV reduction in the FBI and the sham groups. Alterations in MAP and ICP were analyzed with a nonparametric Friedman test followed by post hoc testing using a WilcoxonNeyman-McDonald-Thompson test. All data except data for MAP and ICP were normally distributed. Statistical calculations were made using the computer software $\mathrm{R}$ (version 3.0.0) for Linux.

\section{Results}

\section{Physiological Parameters}

Data for arterial $\mathrm{pH}, \mathrm{Na}^{+} / \mathrm{s}, \mathrm{K}^{+} / \mathrm{s}, \mathrm{BE}$, and Hct for the three groups are presented in Table 1 . Arterial $\mathrm{pH}$ decreased in the 
FBI group ( $p<0.05$ ), but there was no change in $\mathrm{pH}$ in "the sham" and "the control group." $\mathrm{Na}^{+} / \mathrm{s}, \mathrm{K}^{+} / \mathrm{s}, \mathrm{P}_{\mathrm{a}} \mathrm{O}_{2}$, and $\mathrm{P}_{\mathrm{a}-}$ $\mathrm{CO}_{2}$ did not change in any group. Hct increased from baseline to $3 \mathrm{~h}$ after trauma in "the FBI group" ( $p<0.05)$, while there was just a tendency to increase in "the sham group" ( $p=0.08)$. Hct was unchanged in "the control group."

Data for MAP and ICP are presented in Table 2. There was an increase in MAP from $122 \pm 9$ at baseline to $136 \pm 13 \mathrm{mmHg}$ at $3 \mathrm{~h}$ after trauma in "the FBI group" $(p<0.05)$, whereas it tended to decrease in the "sham group" ( $p=0.07)$. MAP did not change in "the control group." ICP increased from $10.4 \pm 3 \mathrm{mmHg}$ at baseline to $15.0 \pm 4 \mathrm{mmHg}$ at $3 \mathrm{~h}$ after trauma in "the FBI group" $(p<0.05)$. There was no change in ICP in "the sham group."

Data for PV for the three groups are presented in Fig. 2. PV decreased from $31.7 \pm 1.7 \mathrm{~mL} / \mathrm{kg}$ at baseline to $20.5 \pm 2.7 \mathrm{~mL} / \mathrm{kg}$ at $3 \mathrm{~h}$ after the trauma in "the FBI group" ( $p<0.01)$. In "the sham group" (exposed only to surgical preparation), PV decreased from $32.7 \pm 2.0 \mathrm{~mL} /$ $\mathrm{kg}$ at baseline to $27.0 \pm 1.4 \mathrm{~mL} / \mathrm{kg}$ at the end of the experiment $(\mathrm{p}<0.01)$. PV at the end of the experiment differed significantly between "the FBI group" and "the sham group" ( $p<0.01)$. In "the control group," plasma volume was $33.1 \pm 1.2 \mathrm{~mL} / \mathrm{kg}$ at baseline and $33.0 \pm$ $1.5 \mathrm{~mL} / \mathrm{kg}$ at the end of the experiment (ns).

\section{Discussion}

The present study on the cat showed that an isolated brain trauma resulted in a significant decrease in PV, with a simultaneous increase in Hct, and this in spite of a continuous infusion of $5 \mathrm{~mL} / \mathrm{kg} / \mathrm{h}$ of saline. It also showed that only about half of the PV reduction could be attributed to the FBI brain trauma, while the rest of the trauma was associated with the preparation. ICP and MAP increased after the FBI trauma, whereas no significant change in MAP could be detected in "the sham group" or in "the control group." There was no change in ICP in "the sham group." There were no alterations in $\mathrm{P}_{\mathrm{a}} \mathrm{O}_{2}, \mathrm{P}_{\mathrm{a}} \mathrm{CO}_{2}, \mathrm{Na}^{+} / \mathrm{s}$, or $\mathrm{K}^{+} / \mathrm{s}$ in any group. $\mathrm{pH}$ and $\mathrm{BE}$ decreased in "the $\mathrm{FBI}$ group." Unchanged $\mathrm{P}_{\mathrm{a}} \mathrm{CO}_{2}$, simultaneously with a decrease in $\mathrm{BE}$, means that the lowered $\mathrm{pH}$ in the FPI group is of metabolic nature.

The ${ }^{125}$ I-dilution technique for measurement of PV is a well-established and reliable method in experimental and clinical studies for both normal and inflammatory states [20-24]. There may have been some overestimation of measured PV because of transcapillary escape of radioactive albumin during the 5-min period between injection of the tracer and collection of the blood sample. Further, free iodine in the injected tracer is distributed quickly to the entire extracellular space, which can result in some overestimation; but the proportion of free iodine was small in this study $(<1.6 \%)$. We conclude that possible sources of error are small and similar in all groups and therefore will not influence the conclusions made below.

The peak FPI trauma was in the range of 1.9-2.2 bars. A previous study on cat using a similar fluid percussion device [17] showed that a peak trauma below about 2.2 bars caused only minimal microscopic subarachnoidal and contusional hemorrhage and EEG changes similar to those observed in human trauma $[17,25]$.

Due to the rigid cranium, there is no space for intracranial expansion. Total brain weight of the cat is about $40 \mathrm{~g}$, and total cerebrospinal volume and intracranial blood volume are less than $2 \mathrm{~mL} / \mathrm{kg}$. This means that just a very small part of the observed loss in PV can be explained by an intracranial bleeding and swelling of the brain, also supported by the relatively small increase in ICP (Table 2).

Table 1 Data (mean $\pm \mathrm{SD}$ ) for $\mathrm{pH}, \mathrm{P}_{\mathrm{a}} \mathrm{O}_{2}, \mathrm{P}_{\mathrm{a}} \mathrm{CO}_{2}$, sodium, potassium, base excess, and hematocrit (Hct) for "the fluid percussion (FBI) group," "the sham group," and "the control group"

\begin{tabular}{|c|c|c|c|c|c|c|c|}
\hline & $\mathrm{pH}$ & $\mathrm{PaO} 2(\mathrm{kPa})$ & $\mathrm{PaCO} 2(\mathrm{kPa})$ & Sodium $(\mathrm{mmol} / \mathrm{L})$ & Potassium $(\mathrm{mmol} / \mathrm{L})$ & Base excess & Hct $(\%)$ \\
\hline \multicolumn{8}{|l|}{ FBI group } \\
\hline Baseline & $7.32 \pm 0.04$ & $11.5 \pm 0.7$ & $4.9 \pm 0.3$ & $152 \pm 1$ & $3.6 \pm 0.3$ & $-6.0 \pm 1.8$ & $35 \pm 3$ \\
\hline $\begin{array}{l}\text { End of exp. } \\
\text { Sham group }\end{array}$ & $7.25 \pm 0.04 *$ & $10.9 \pm 1.3$ & $5.1 \pm 0.1$ & \multicolumn{4}{|c|}{ Sham group } \\
\hline Baseline & $7.30 \pm 0.05$ & $11.1 \pm 0.8$ & $4.5 \pm 0.7$ & $153 \pm 2$ & $3.4 \pm 0.3$ & $-7.5 \pm 1.9$ & $34 \pm 2$ \\
\hline $\begin{array}{l}\text { End of exp. } \\
\text { Control grou }\end{array}$ & $7.32 \pm 0.06$ & $11.4 \pm 0.7$ & $4.5 \pm 0.4$ & $151 \pm 2$ & $3.8 \pm 0.6$ & $-9.0 \pm 1.9$ & $40 \pm 5$ \\
\hline Baseline & $7.34 \pm 0.06$ & $10.6 \pm 1.3$ & $4.4 \pm 0.4$ & $152 \pm 2$ & $3.4 \pm 0.2$ & $-6.6 \pm 1.5$ & $37 \pm 4$ \\
\hline End of exp. & $7.34 \pm 0.05$ & $11.0 \pm 1.2$ & $4.4 \pm 0.3$ & $152 \pm 3$ & $3.3 \pm 0.2$ & $-6.4 \pm 1.5$ & $36 \pm 5$ \\
\hline
\end{tabular}

$* p<0.05$ compared to baseline 
Table 2 Data (mean \pm SD) for mean arterial blood pressure (MAP, in $\mathrm{mmHg}$ ) at baseline and 1,2 , and $3 \mathrm{~h}$ after baseline for "the fluid percussion" (FBI) group," "the sham group," and "the control group." Data (mean $\pm \mathrm{SD}$ ) for intracranial pressure (ICP, in $\mathrm{mmHg}$ ) at baseline and 1,2, and $3 \mathrm{~h}$ after baseline are presented for "the FBI group" and "the sham group"

\begin{tabular}{|c|c|c|c|c|}
\hline & Baseline & $1 \mathrm{~h}$ after baseline & $2 \mathrm{~h}$ after baseline & $3 \mathrm{~h}$ after baseline \\
\hline \multicolumn{5}{|l|}{ FBI group } \\
\hline MAP (in $\mathrm{mmHg}$ ) & $122 \pm 9$ & $134 \pm 15$ & $134 \pm 20$ & $135 \pm 13 *$ \\
\hline ICP (in $\mathrm{mmHg}$ ) & $10.4 \pm 3$ & $13.0 \pm 6$ & $14.9 \pm 5$ & $15.0 \pm 4^{*}$ \\
\hline \multicolumn{5}{|l|}{ Sham group } \\
\hline MAP (in $\mathrm{mmHg}$ ) & $119 \pm 19$ & $108 \pm 21$ & $115 \pm 24$ & $112 \pm 21$ \\
\hline ICP (in $\mathrm{mmHg}$ ) & $9.6 \pm 1.5$ & $9.6 \pm 2.1$ & $10.5 \pm 2.6$ & $10.4 \pm 1.8$ \\
\hline \multicolumn{5}{|l|}{ Control group } \\
\hline MAP (in $\mathrm{mmHg}$ ) & $120 \pm 17$ & $122 \pm 22$ & $122 \pm 24$ & $124 \pm 23$ \\
\hline
\end{tabular}

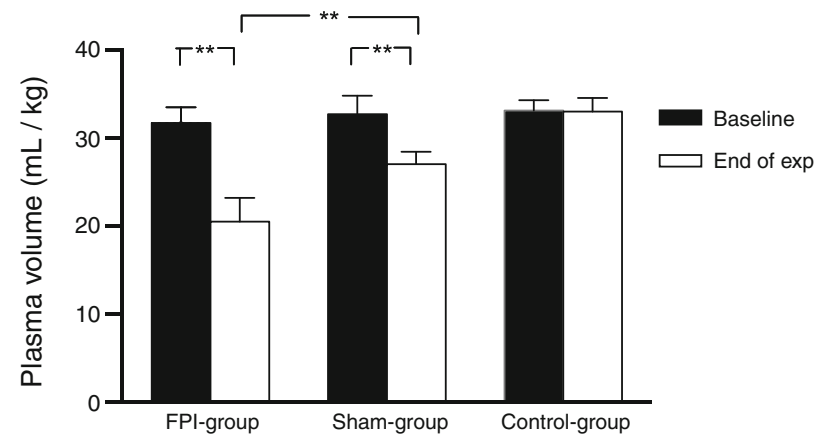

Fig. 2 Plasma volume (PV) at baseline and at the end of the experiment $3 \mathrm{~h}$ later for the 3 groups ("the "fluid percussion (FBI) group" + "the sham group," and "the control group"). Student's $t$ test for paired observations was used for comparison of PV at baseline and at the end of the experiments for each group. Student's $t$ test for unpaired observations was used for comparing PV reduction between "the FBI group" and "the sham group" $(* * p<0.01)$

The simultaneous increase in Hct and decrease in PV, therefore, most likely can be explained by a systemic loss of plasma.

As mentioned, traumatic brain injury triggers an inflammatory response, which is thought to contribute to the secondary injuries and to brain edema [2-7, 17]. We hypothesized that a brain trauma induced a systemic inflammation, which may induce a systemic vascular leak and contribute to the observed decrease in PV $[12,26]$. Previous experimental studies have shown that brain trauma initiates a cascade of multiple anti- and proinflammatory pathways with permeability-increasing properties, such as release of various cytokines such as IL6, TNF alpha, and IL10 $[8,26]$. Some further proinflammatory substances and mechanisms associated with a head injury are the release of chemokines, prostaglandins, and free radicals $[4,5,27-29]$. Also the existence of a general hyperadrenergic state with increase in sympathetic discharge may contribute to PV leak via effect on blood pressure or indirectly via endothelial effects $[28,29]$. So far, however, no specific anti-inflammatory drug or blockade of inflammatory pathways has shown beneficial effects on outcome in clinical studies in head injury $[1,27,30,31]$.

Our results of an increase in MAP following brain trauma despite a significant reduction in PV most likely are secondary to a trauma-induced increase in sympathetic activity and catecholamine release [28, 31, 32]. An increase in blood pressure after a head trauma was also found in the previous fluid percussion study on the cat [17]. Increases in blood pressure are also common after a head trauma in man [32].

Both clinical and experimental studies have demonstrated that an increase in arterial blood pressure increases vascular leak of fluid and macromolecules, particularly in inflammatory states and most likely due to an increase in microvascular hydrostatic pressure [33, 34]. Based on this, it could be speculated that part of the decrease in PV seen in "the FBI group" may be an effect of increase in blood pressure.

To evaluate the loss in PV caused by the brain trauma, the amount of PV loss in "the sham group" must be subtracted from the PV loss in "the FBI group." We found that about half of the total loss in PV in the present study was a consequence of the surgical preparation and half of the brain trauma.

Our finding that brain trauma induces a decrease in PV means that hypovolemia is a potential contributor of reduced cerebral circulation and secondary brain injuries, especially in areas with compromised blood flow from start, such as the penumbra zone [11]. If applicable to man, hypovolemia should be considered in patients after a traumatic brain injury. That the hypovolemia is not reflected in a decrease in blood pressure agrees with previous studies and suggests that blood pressure alone is a poor resuscitation endpoint in brain trauma $[35,36]$.

The brain trauma in man is different from a fluid percussion brain trauma. It was standardized in the present 
study and does not reflect the case mix and variability of head trauma in clinical practice, and it includes cranial burr holes. The inflammatory response after a head injury may also be different between cat and man. Loss of plasma in man after a head trauma finds support by the fact that albumin concentration in plasma is lowered, most likely due to transcapillary leak $[12,15]$, and that plasma fluid substitution is of importance to preserve hemodynamic stability $[2,13]$. Cranial boreholes in man are much smaller relative to the size of the cranium than those in the present study on the cat and, hence, the borehole trauma is proportionally smaller in man. If borehole trauma influences PV loss, as indicated from the present results, the effect of burr holes on PV is likely to be less pronounced in man than in the cat. However, it is possible that larger cranial openings in patients, such as those performed for decompressive craniotomy or for evacuation of a large subdural hematoma, may influence PV.

In conclusion, to our knowledge, this is the first study that specifically shows an isolated severe head trauma resulting in a relatively rapid loss of PV, most likely due to a general transcapillary leak, with preserved or even increased MAP. If applicable to man, the results suggest that brain trauma may result in hypovolemia unrecognized by a lowered MAP, which could contribute to poor outcome.

Acknowledgements We thank Helen Axelberg and Christine Wikstrand for excellent technical assistance and Attila Frigyesi for help with the statistical analyses.

Funding Financial support from Region Skåne, ALF, Sweden (\#18401); the Swedish Research Council (\#11581); and Berger Foundation, Stockholm, Sweden.

\section{Compliance with Ethical Standards}

Conflict of interest There are no conflicts of interest for any of the authors.

Open Access This article is distributed under the terms of the Creative Commons Attribution 4.0 International License (http:// creativecommons.org/licenses/by/4.0/), which permits unrestricted use, distribution, and reproduction in any medium, provided you give appropriate credit to the original author(s) and the source, provide a link to the Creative Commons license, and indicate if changes were made.

\section{References}

1. Marshall LF. Head injury: recent past, present, and future. Neurosurgery. 2000;47:546-61 (Review).

2. Werner C, Engelhard K. Pathophysiology of traumatic brain injury. Br J Anaesth. 2007;99:4-9.
3. Finnie JW. Neuroinflammation: beneficial and detrimental effects after traumatic brain injury. Inflammopharmacology. 2013;21:309-20.

4. Lenzlinger PM, Morganti-Kossmann MC, Laurer HL, Mcintosh TK. The duality of the inflammatory response to traumatic brain injury. Mol Neurobiol. 2001;24:169-81.

5. Helmy A, Carpenter KL, Menon DK, Pickard JD, Hutchinson PJ. The cytokine response to human traumatic brain injury: temporal profiles and evidence for cerebral parenchymal production. J Cereb Blood Flow Metab. 2011;31:658-70.

6. Cortez SC, Mcintosh TK, Noble LJ. Experimental fluid percussion brain injury: vascular disruption and neuronal glial alterations. Brain Res. 1989;482:271-82.

7. Young $\mathrm{AB}$, Ott LG, Beard D. The acute-phase response of the brain-injured patient. J Neurosurg. 1988;69:375-80.

8. Fleck A, Raines G, Hawker F, et al. Increased vascular permeability: a major cause of hypoalbuminaemia in disease and injury. Lancet. 1985;1:781-4.

9. Lenz A, Franklin GA, Cheadle WG. Systemic inflammation after trauma. Injury. 2007;38:1336-45.

10. Bansch P, Lundblad C, Grände PO, Bentzer P. Prostacyclin reduces plasma volume loss after skeletal muscle trauma in the rat. J Trauma Acute Care Surg. 2012;73:1531-6.

11. Rise IR, Risöe C, Kirkeby OJ. Cerebrovascular effects of high intracranial pressure after moderate hemorrhage. J Neurosurg Anesthesiol. 1998;10:224-30.

12. McClain CJ, Hennig B, Ott LG, Goldbaum S, Young AB. Mechanisms and implications of hypoalbuminemia in head-injured patients. J Neurosurg. 1988;69:386-92.

13. Chesnut RM, Marshall LF, Klauber MR, et al. The role of secondary brain injury in determining outcome from severe head injury. J Trauma. 1993;34:216-22.

14. Chesnut RM. Secondary brain insults after head injury: clinical perspectives. New Horiz. 1995;3:366-75.

15. Grände PO. The "Lund Concept" for the treatment of severe head trauma: physiological principles and clinical application. Intensive Care Med. 2006;32:1475-84 (Review).

16. Bullock R, Chesnut RM, Clifton $G$ et al. Guidelines for the management of severe head injury. Brain Trauma Foundation. Eur J Emerg Med. 1996;3:109-27.

17. Sullivan HG, Martinez J, Becker DP, Miller JD, Griffith R, Wist AO. Fluid-percussion model of mechanical brain injury in the cat. J Neurosurg. 1976;45:520-34.

18. McIntosh TK, Vink R, Noble L, et al. Traumatic brain injury in the rat: characterization of a lateral fluid-percussion model. Neuroscience. 1989;28:233-44.

19. Bentzer P, Mattiasson G, McIntosh TK, Wieloch T, Grände PO. Infusion of prostacyclin following experimental brain injury in the rat reduces cortical lesion volume. J Neurotrauma. 2001;18:275-85.

20. Persson J, Grände PO. Plasma volume expansion and transcapillary fluid exchange in skeletal muscle of albumin, dextran, gelatin, hydroxyethyl starch, and saline after trauma in the cat. Crit Care Med. 2006;34:2456-62.

21. Dubniks M, Persson J, Grände PO. Plasma volume expansion of 5\% albumin, 4\% gelatin, 6\% HES 130/0.4, and normal saline under increased microvascular permeability in the rat. Intensive Care Med. 2007;33:293-9.

22. Margason MP, Soni NC. Plasma volume measurement in septic patients using an albumin dilution technique: comparison with the standard radio-labelled albumin method. Intensive Care Med. 2005;31:289-95.

23. Bark B, Persson J, Grände PO. Importance of the infusion rate for the plasma expanding effect of 5\% albumin, 6\% HES, 130/0.4, $4 \%$ gelatin, and $0.9 \% \mathrm{NaCl}$ in the septic rat. Crit Care Med. 2013;41:857-66. 
24. Valeri CR, Cooper AG, Pivaceek LE. Limitations of measuring blood volume with iodinated $\mathrm{I}^{125}$ serum albumin. Arch Intern Med. 1973;132:534-8.

25. Nuwer MR, Hovda DA, Schrader LM, Vespa PM. Routine and quantitative EEG in mild traumatic brain injury. Clin Neurophysiol. 2005;116(9):2001-25.

26. Hergenroeder GW, Moore AN, McCoy JP Jr, et al. Serum IL-6: a candidate biomarker for intracranial pressure elevation following isolated traumatic brain injury. J Neuroinflammation. 2010;7(19):1-13. doi:10.1186/1742-2094-7-19.

27. Kumar A, Loane DJ. Neuroinflammation after traumatic brain injury: opportunities for therapeutic intervention. Brain Behav Immun. 2012;26:1191-201 (Review).

28. Di Battista AP, Rizoli SB, Lejniecks B, Min A, et al. Sympatoadrenal activation is associated with acute traumatic coagulopathy and endotheliopathy in isolated brain injury. Shock. 2016;46(3 suppl 1):96-103.

29. Di Battista AP, Rhind SG, Hutchison MG, et al. Inflammatory cytokine and chemokine profiles are associated with patient outcome and the hyperadrenergic state following acute brain injury. J Neuroinflammation. 2016;13:40. doi:10.1186/s12974016-0500-3.
30. Bergold PJ. Treatment of traumatic brain injury with anti-inflammatory drugs. Exp Neurol. 2016;275:367-80 (Review).

31. Tuttolomondo A, Pecoraro R, Pinto A. Studies of selective TNF inhibitors in the treatment of brain injury from stroke and trauma: a review of the evidence to date. Drug Des Devel Ther. 2014;8:2221-38.

32. Clifton GL, Ziegler MG, Grossman RG. Circulating catecholamines and sympathetic activity after head injury. Neurosurgery. 1981;8:10-4.

33. Dubniks M, Persson J, Grände PO. Effect of blood pressure on plasma volume loss in the rat under increased permeability. Intensive Care Med. 2007;33:2192-8.

34. Nygren A, Redfors B, Thorén A, Ricksten SE. Norepinephrine causes a pressure-dependent plasma volume decrease in clinical vasodilatory shock. Acta Anaesthesiol Scand. 2010;54:814-20.

35. Shippy CR, Appel PL, Shoemaker WC. Reliability of clinical monitoring to assess blood volume in critically ill patients. Crit Care Med. 1984;12:107-12.

36. Stéphan F, Flahault A, Dieudonné N, Hollande J, Paillard F, Bonnet F. Clinical evaluation of circulating blood volume in critically ill patients: contribution of a clinical scoring system. $\mathrm{Br}$ J Anaesth. 2001;86:754-62. 